\title{
NURSING STUDENTS' EXPERIENCES OF DRUG ADMINISTRATION IN PEDIATRIC WARDS: A QUALITATIVE STUDY
}

Mitra Soltanian ${ }^{1}$, Farhood Nikouee ${ }^{2}$

${ }^{1}$ Department of Nursing, Shiraz University of Medical Sciences, Shiraz, Iran

${ }^{2}$ Department of Community Medicine, Fasa University of Medical Sciences, Fasa, Iran

\section{Background}

Undergraduate nursing students are involved in clinical nursing care especially in drug administration.

They may commit a drug error that is more likely to occur due to the fact that they are learning. Drug administration is complex, particularly in pediatric wards; thus, the present study aimed to explain nursing students' experiences of drug administration in pediatric wards.

\section{Methods}

In this study, the qualitative approach and conten analysis method were used. Twenty five undergraduate nursing students were selected for participation using purposive sampling. Data was collected through semi-structured interviews. Using continuous analysis, data collection and comparison were performed at the same time.

\section{References}

Aein, F., Alhani, F., Mohammadi, E., et al. (2011). Struggling to create new boundaries: A grounded theory study of collaboration between nurses and parents in the care process in Iran. Journal of Advanced Nursing, 67(4), 841-853.

Ahmed, N. G., Adam, S. M., \& Al-Moniem, A (2011). Patient Safety: Assessing Nurses' Perception and Developing an Improvement Plan. Life Science Journal, 8(2), 53-64.

Boztepe, H., Özdemir, H., Karababa, C., et al (2014). Difficulties experienced during preparation and administration of oral drugs. Türk Ped Arș, 49, 231-237

\section{Results}

From the rich description of the participants, 550 initial codes were extracted.

After several reviews and a summarization based on similarity and congruence, these codes were classified. These themes were identified as conceptual or abstract and placed in 4 main categories. The main categories are as follows:

\section{Difficult and different field experiment}

Since the work of pediatric nurses in Shiraz, Iran is divided according to the case method of assignment, Pediatric nursing students are responsible for whole care giving as well. Indeed, the multiplicity of tasks affected the quality of drug administration by students in pediatric wards. Nursing student (18) stated:

"Medication administration is really difficult in pediatric wards. If you administer 10 milligrams of drugs instead of 1 milligrams, the child will react quickly!"

\section{Panic of error}

The experience of the majority of nursing students showed that they have fear of error during drug administration.

Nursing student (10) with stated

"It is difficult to calculate pediatric drugs. It occurs to me that I have made mistakes in such complex calculations! ... I fear really!"

\section{Need to be monitor}

Participants stated that due to knowledge and experience deficit in relation to medication instructors. Nursing student (12) said:

"One patient had to take Phenytoin intravenously but I had spilled Phenytoin into dextrose water Then I saw the contents of the patient's micro set called my instructor!"

\section{Time pressure}

Nursing students are busy and do not have time to study the drugs. They can only try to give their medications on time.

A nursing student stated :

"We are willing to learn all the medicines in the children's ward, but unfortunately for two weeks, there is very little time." administration, they need to be monitor by their were sediment... I shocked and immediately

\section{Conclusion}

Given the importance of safety during drug administration and its effects on the health of children, the results of this study can be applied by nursing instructors for better education of pediatric drug administration. Nursing educators can play an important role in reducing medication errors and increasing the trust of the child and the family by supervising students in the process of drug administration.

\section{Keywords}

Drug administration, Nursing students, Pediatric wards, Qualitative study

\section{Acknowledgment}

Undergraduate nursing students in Shiraz University of Medical Sciences, Iran that participated in the study have been thanked.

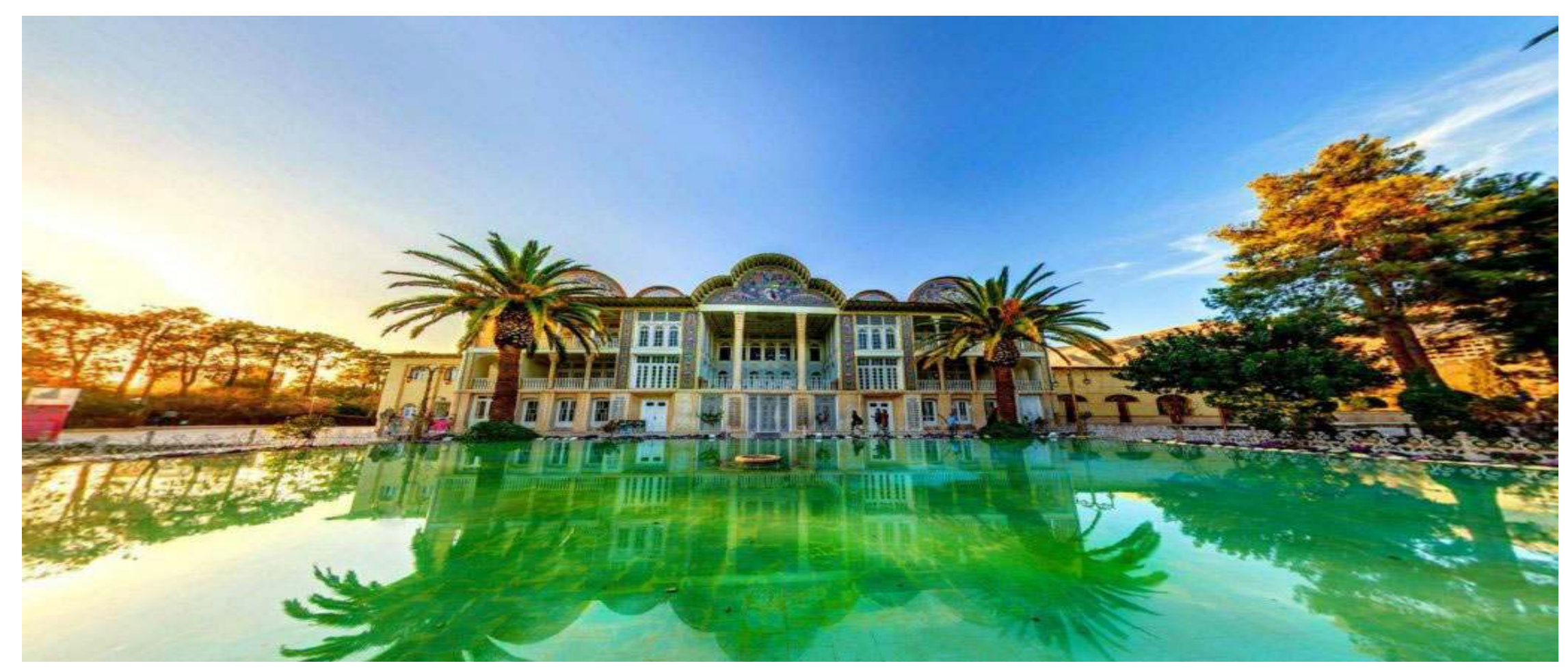

